\title{
Biotransformation of ginsenoside Rb1 via the gypenoside pathway by human gut bacteria
}

Hong Shen ${ }^{1,2+}$, Weng-Im Leung ${ }^{1 \dagger}$, Jian-Qing Ruan ${ }^{1}$, Song-Lin Li ${ }^{2}$, Jacky Pui-Cheong Lei ${ }^{3}$, Yi-Tao Wang ${ }^{1}$ and Ru Yan ${ }^{1 *}$

\begin{abstract}
Background: Bacterial conversion of ginsenosides is crucial for the health-promoting effects of ginsenosides. Previous studies on the biotransformation of ginsenoside Rb1 (Rb1) by gut bacteria have focused on the ginsenoside $\mathrm{Rd}(\mathrm{Rd})$ pathway (Rb1 $\rightarrow \mathrm{Rd} \rightarrow$ ginsenoside F2 (F2) $\rightarrow$ compound K (Cpd K)). This study aims to examine the gypenoside pathway in human gut bacteria in vitro.

Methods: The metabolic pathways of ginsenoside Rb1 and its metabolites ginsenoside Rd and gypenoside XVII in human gut bacteria were investigated by incubating the compounds anaerobically with pooled or individual gut bacteria samples from healthy volunteers. Ginsenoside Rb1, the metabolites generated by human gut bacteria, and degraded products in simulated gastric fluid (SGF) were qualitatively analyzed using an LC/MSD Trap system in the negative ion mode and quantitatively determined by HPLC-UV analysis.

Results: When incubated anaerobically with pooled gut bacteria, Rb1 generated five metabolites, namely Rd, F2, Cpd K, and the rare gypenosides XVII (G-XVII) and LXXV (G-LXXV). The gypenoside pathway (Rb1 $\rightarrow$ G-XVII $\rightarrow \mathrm{G}-\mathrm{LXXV} \rightarrow \mathrm{Cpd} \mathrm{K}$ ) was rapid, intermediate, and minor, and finally converted Rb1 to Cpd K via G-XVII $\rightarrow$ F2 (major)/G-LXXV (minor). Both the Rd and gypenoside pathways exhibited great inter-individual variations in age-and sex-independent manners $(P>0.05)$. Rb1 was highly acid-labile and degraded rapidly to form $\mathrm{F} 2$, ginsenoside Rg3, ginsenoside Rh2, and Cpd K, but did not generate the gypenosides in SGF. The formation of the gypenosides might be explained by the involvement of a gut bacteria-mediated enzymatic process.
\end{abstract}

Conclusions: Rb1 was metabolized to G-XVII, F2 (major) or G-LXXL (minor), and finally Cpd K by human gut bacteria in vitro.

\section{Background}

Ginsenosides are the major bioactive components in Panax, including Panax ginseng, Panax quinquefolium, and Panax notoginseng [1], which are the most popular herbs used for medicinal and nutritional purposes in China, Japan, Korea, and some Western countries. Two dammarane-type triterpene $O$-glycosides, namely 20(S)protopanaxadiol (PPD) and 20(S)-protopanaxatriol, are the major ginsenosides in different parts of Panax, including the flower bud, berry, crown, rootlet, side root, seed bud, seed, stem, and leaf $[2,3]$, and their differently processed herbal products [4]. As one of the most important PPDtype ginsenosides, ginsenoside Rb1 (Rb1) has exhibited

\footnotetext{
* Correspondence: ruyan@umac.mo

†Equal contributors

'State Key Laboratory of Quality Research in Chinese Medicine, Institute of Chinese Medical Sciences, University of Macau, Macao, China

Full list of author information is available at the end of the article
}

various pharmacological activities, including neuroprotective, antitumor, cardiovascular-protective, and anti-aging effects, in many in vitro and in vivo models [5-7].

The intestinal absorption of glycosides in plants or foods is poor, while their metabolites generated by intestinal microflora are more permeable and bioactive [8-11]. The oral bioavailability of PPD-type ginsenosides is generally low $(<10 \%)$ [12]. The bacterial metabolites are the main forms transported across the epithelial membrane and are most likely to be the real in vivo active forms [13]. This finding has led to research on microbial metabolism and the pharmacological activities of the resultant metabolites of ginsenosides including Rb1 [14-16]. Hasegawa et al. [17] proposed metabolism of $\mathrm{Rb} 1$ via the ginsenoside $\mathrm{Rd}$ (Rd) pathway by human intestinal bacteria in vitro, which was initiated at the $\mathrm{C}-20$ glucose $(\mathrm{Rb} 1 \rightarrow \mathrm{Rd} \rightarrow$ ginsenoside F2 (F2) $\rightarrow$ Compound K (Cpd K)), and the gypenoside XVII (G-XVII) pathway, which was initiated by removal of

\section{Biomed Central}


the $\mathrm{C}$-3 glucose $(\mathrm{Rb} 1 \rightarrow \mathrm{G}-\mathrm{XVII} \rightarrow$ gypenoside LXXV (GLXXV) $\rightarrow$ Cpd K). However, the gypenoside pathway of $\mathrm{Rb} 1$ was only speculated from the results of TLC, and the data were not provided by the authors $[18,19]$.

The formation of G-XVII from Rb1 has been investigated in several metabolic studies with individual fungal strains [20-22]. Moreover, G-XVII was detected in vivo in rats receiving oral administration of $\mathrm{Rb} 1[23,24]$. Although there are no reports on the formation of G-LXXV in rats, the presence of G-XVII suggests the existence of both the gypenoside and Rd pathways of Rb1 metabolism in rats. In plasma and urine samples from healthy subjects who received oral administration of a ginseng extract, only $\mathrm{Rd}$ and Cpd K were detected [25,26]. The gypenoside pathway of $\mathrm{Rb} 1$ metabolism in the human body remains to be confirmed.

Ginsenoside $\mathrm{Rd}$ and $\mathrm{Cpd} \mathrm{K}$ have been shown to possess potent pharmacological activities [27], contributing to the beneficial effects of Rb1. The available, albeit limited, reports on the bioactivities of gypenosides have described that the gypenosides from Gynostemma pentaphyllum have anticancer, antioxidative, and antihyperlipidemic effects $[28,29]$. It is important to know whether gypenosides can be formed from ginsenoside Rb1 by bacterial biotransformation in the human gut lumen.

Gypenosides could be generated from ginsenoside $\mathrm{Rb} 1$ via a non-enzymatic process in vivo, such as degradation in the acidic environment of the stomach [30], other than biotransformation by gut bacteria. Several studies have reported the degradation of several ginsenosides, including Rb1, in acidic environment [31,32]. However, the aspect of whether Rb1 is degraded to form gypenosides remains unclear.

This study aims to examine the gypenoside pathway in human gut bacteria in vitro. The biotransformation of Rb1 by human gut bacteria was characterized by highperformance liquid chromatography with a UV detector (HPLC-UV) and HPLC-mass spectrometry (MS) analyses. The gypenoside pathway of Rb1 was investigated and compared with the Rd pathway by incubating Rb1, Rd, and G-XVII separately with pooled human gut bacterial samples. The inter-individual variations in the G-XVII and $\mathrm{Rd}$ pathways were also characterized with gut bacterial samples from 58 individuals of both sexes and different ages. The stabilities of $\mathrm{Rb} 1$ and $\mathrm{Rd}$ in simulated gastric fluid (SGF) were examined to rule out the generation of these gypenosides under the acidic gastric environment.

\section{Methods}

\section{Chemicals, reagents, and materials}

Ginsenoside Rb1, Rd, F2, Rg3, Cpd K, Rh2, G-XVII, and Rg1 were supplied by Chengdu Must Biotechnology Co. Ltd. (Chengdu, China). The purity was $>98 \%$ (HPLC$\mathrm{UV})$. The $\mathrm{BBL}^{\mathrm{ma}}$ Brain Heart Infusion (BHI) medium,
GasPak $^{\text {ma }}$ EZ anaerobe container system with an indicator, and $\mathrm{GasPak}^{\mathrm{Tm}}$ EZ large incubation container were purchased from Becton Dickinson (Franklin Lakes, NJ, USA). L-cystine was purchased from Research Organics Inc. (Cleveland, OH, USA). Dimethyl sulfoxide (DMSO), bovine hemin, and vitamin K1 were supplied by SigmaAldrich (St. Louis, MO, USA). Methanol, 1-butanol, and acetonitrile were HPLC-grade and purchased from Merck (Darmstadt, Germany). Dulbecco's phosphate-buffered saline (PBS) was provided by Life Technologies (Carlsbad, CA, USA). Hydrochloric acid and sodium carbonate (analytical grade) were purchased from Sigma-Aldrich (St. Louis, MO, USA). Deionized water was prepared in-house using a Milli-Q purification system (Millipore, Bedford, MA, USA).

\section{Instrumentation and analytical conditions}

Chromatographic separation was performed on an Agilent 1200 Series HPLC apparatus (Agilent Technologies, Santa Clara, CA, USA) equipped with a vacuum degasser, a binary pump, and an autosampler, and connected to a diode array detector (DAD). Samples were loaded onto an Alltima C18 column $(250 \times 4.6 \mathrm{~mm}, 5 \mu \mathrm{m})$. The column temperature was maintained at $25^{\circ} \mathrm{C}$. The mobile phase consisted of water (A) and acetonitrile (B) and flowed at $1.5 \mathrm{~mL} / \mathrm{min}$. The following gradient elution program was used for samples obtained from bacterial incubations: 010 min, $19-20 \%$ B; $10-28 \mathrm{~min}, 20-30 \%$ B; $28-40$ min, $30-$ $60 \% \mathrm{~B} ; 40-48 \mathrm{~min}, 60-100 \% \mathrm{~B}$. The elution program was modified when the incubations of ginsenosides with SGF were analyzed as follows: $0-10 \mathrm{~min}, 19-20 \% \mathrm{~B} ; 10-28 \mathrm{~min}$, $20-30 \%$ B; $28-35 \mathrm{~min}, 30-60 \%$ B; 35-45 min, $60-100 \%$ B. $\mathrm{Rb} 1$ and its bacterial metabolites were monitored at $203.4 \mathrm{~nm}$ and their UV absorbance was recorded over 200-400 $\mathrm{nm}$. The injection volume was $5 \mu \mathrm{L}$.

MS analysis was performed on an liquid chromatograph/mass selective detector (LC/MSD) Trap system (Agilent Technologies, Palo Alto, CA, USA) equipped with an ion-trap mass spectrometer with an electrospray ionization (ESI) interface. Agilent ChemStation for LC 3D System software (Rev. B. 01. 03-SR2) (Agilent Technologies, Santa Clara, CA, USA) was used for instrument control, data acquisition, and data management. Except for replacement of the water with $50 \mathrm{mM}$ ammonium acetate in water, the mobile phase composition and gradient elution program were the same as those for the above HPLC analysis method for human gut bacteria samples. The mass spectrometer was operated in the negative ion mode with the following conditions: drying gas $\left(\mathrm{N}_{2}\right), 8 \mathrm{~L} / \mathrm{min}$; temperature, $325^{\circ} \mathrm{C}$; nebulizer pressure, $30 \mathrm{psi}$; scan range, $\mathrm{m} / z$ 100-1400. The ESIMS/MS conditions were as follows: negative ion mode; separation width, 4; fragment amplification, $1.0 \mathrm{~V}$; scan range, $m / z$ 100-1400. 


\section{Preparation of human gut bacteria}

The medium was prepared according to our previous report [33]. Briefly, $100 \mathrm{~mL}$ of autoclaved BHI medium $(3.7 \mathrm{~g} / 100 \mathrm{~mL})$ was supplemented with $0.05 \mathrm{mg}$ of vitamin $\mathrm{K} 1,0.5 \mathrm{mg}$ of bovine hemin, and $50 \mathrm{mg}$ of L-cystine. The fecal samples (healthy Chinese, 18-92 years old) were provided by Kiang Wu Hospital and the experimental protocol is approved by Kiang Wu Hospital and University of Macau before conduct. Human gut bacteria suspensions were prepared at $4^{\circ} \mathrm{C}$ according to our previous report [33] with minor modifications. Fecal samples were freshly collected and pooled at $1 \mathrm{~g}$ each for identification of Rb1 metabolic pathways, or individually processed at $5 \mathrm{~g}$ each for characterization of individual variations in Rb1 metabolism. The individual or pooled fecal samples were mixed with $20 \mathrm{~mL}$ of $\mathrm{BHI}$ medium and the resulting suspensions were centrifuged at $200 \times g$ for $5 \mathrm{~min}$. The supernatants were then centrifuged at $5000 \times g$ for $30 \mathrm{~min}$. The human gut bacteria suspensions were obtained by resuspension of the bacterial precipitates in $5 \mathrm{~mL}$ of $\mathrm{BHI}$ medium.

\section{Biotransformation of $\mathrm{Rb} 1$ by human gut bacteria}

Biotransformation assays of Rb1 were conducted with pooled or individual human gut bacteria samples to examine the existence of the gypenoside pathway and compare it with the $\mathrm{Rd}$ pathway. A high concentration of $\mathrm{Rb} 1$ was used to capture the minor formation and quantitative variations in the metabolites formed from the minor gypenoside pathway based on the great individual variations in gut bacteria compositions and metabolic capabilities [34]. The anaerobic incubation system contained $250 \mu \mathrm{L}$ of gut bacteria suspension, $100 \mu \mathrm{L}$ of $\mathrm{Rb} 1$ in DMSO (final concentration, $100 \mathrm{mM} \mathrm{Rb1}$ ), and $4.75 \mathrm{~mL}$ of BHI medium. The incubation system was maintained in an anaerobic state at $37^{\circ} \mathrm{C}$ using the Gas$\mathrm{Pak}^{\mathrm{TM}}$ EZ anaerobe container system.

The metabolic pathway and time-course of Rb1 metabolism by human gut bacteria were characterized in five independent experiments using pooled samples. In each experiment, the reaction of Rb1 with a human gut bacteria suspension was conducted in duplicate. Control reactions were conducted in parallel by adding $250 \mu \mathrm{L}$ of PBS (pH 7.0) instead of gut bacteria suspension. The reactions were terminated at $0,2,4,12,18,24,36$, and $48 \mathrm{~h}$, respectively, by adding $15 \mathrm{~mL}$ of 1-butanol followed by immediate centrifugation at $5000 \times g$ for $30 \mathrm{~min}$ to remove the bacteria. The resulting supernatants were mixed with $100 \mu \mathrm{L}$ of ginsenoside Rg1 (final concentration, $100 \mathrm{mM}$ ) as an internal standard (IS), and each mixture was extracted twice with water-saturated 1-butanol. The organic layers were combined and dried by rotary evaporation (BUCHI, Flavil, Switzerland). The residue was reconstituted in $0.2 \mathrm{~mL}$ of methanol, and an aliquot $(5 \mu \mathrm{L})$ was subjected to HPLC-UV or HPLC-MS analysis.
Inter-individual variations in the gypenoside and $\mathrm{Rd}$ pathways were investigated by incubating Rb1 with gut bacteria suspensions from different individuals under the same conditions described above, and the incubated samples collected at $18 \mathrm{~h}$ were processed as described above. Samples were analyzed by HPLC-UV, and the peak area ratio data of each analyte were collected for comparison.

\section{Biotransformation of Rd and G-XVII by human gut bacteria}

The metabolism of the two positional isomers $\mathrm{Rd}$ and G-XVII by human gut bacteria was investigated by incubation with the same human gut bacteria sample in parallel to identify the pathways between Rd/G-XVII and Cpd K. The anaerobic incubation system contained $20 \mu \mathrm{L}$ of gut bacteria suspension, $10 \mu \mathrm{L}$ of ginsenoside Rd or G-XVII (final concentration, $100 \mu \mathrm{M}$ Rd or G$\mathrm{XVII}$ ), and $170 \mu \mathrm{L}$ of $\mathrm{BHI}$ medium. The concentrations of Rd and G-XVII were determined based on the high amounts of all metabolites determined from a preliminary study. Each reaction was conducted in triplicate. Control reactions without gut bacteria were conducted in parallel.

Reactions were terminated at $0,2,4,6,8,12,18,24$, 36 , and $48 \mathrm{~h}$, respectively, by adding $1.2 \mathrm{~mL}$ of 1 -butanol followed by centrifugation at $5000 \times g$ for $30 \mathrm{~min}$ to remove the bacteria. After adding $10 \mu \mathrm{L}$ of ginsenoside Rg1 (final concentration, $100 \mu \mathrm{M}$ Rg1) as an internal standard, the resulting mixture was processed in the same manner described above before being subjected to HPLC-UV analysis.

\section{Stabilities of Rb1 and Rd in SGF}

SGF was prepared by diluting $3.84 \mathrm{~mL}$ of hydrochloric acid to $1000 \mathrm{~mL}$ with deionized water ( $\mathrm{pH} 1.2$ ) according to the Chinese Pharmacopoeia [35]. Ten microliters of ginsenoside $\mathrm{Rb} 1$ or $\mathrm{Rd}$ in DMSO (final concentration, 71.4 $\mu \mathrm{M}$ ) was mixed with $200 \mu \mathrm{L}$ of SGF, and kept at $37^{\circ} \mathrm{C}$ for different time intervals $(0,20,40,60,90,150$, 180 and $300 \mathrm{~min}$ ) before adding $70 \mu \mathrm{L}$ of $0.1 \mathrm{~mol} / \mathrm{L}$ $\mathrm{Na}_{2} \mathrm{CO}_{3}$ to examine the acidic stability. Each reaction was conducted in triplicate. The mixture was shaken for $1 \mathrm{~min}$ by vortexing and centrifuged at $14,000 \times g$ for $5 \mathrm{~min}$. The upper layer was decanted and an aliquot $(20 \mu \mathrm{L})$ was subjected to HPLC-UV analysis.

\section{Calibration curves of Rb1 and its metabolites Rd, F2, G-XVII, and Cpd $\mathrm{K}$ in human gut bacteria}

Serial concentrations of Rb1, Rd, G-XVII, F2, and Cpd K were prepared in DMSO, and mixed with a pooled human gut bacteria suspension and BHI medium as described in the section entitled Biotransformation of $R b 1$ by Human Gut Bacteria. The resulting mixtures were 
immediately extracted with 1-butanol and centrifuged $(5000 \times g, 30 \mathrm{~min})$. The organic layers were processed in the same manner described above and then subjected to HPLC-UV analysis. Calibration curves were constructed by plotting the peak area ratio of each analyte to the IS $(\mathrm{Y})$ as a function of the analyte concentration $(\mathrm{X})$ in the reaction system.

For measurements of the intra-day precision and accuracy, three concentration levels for each standard (low, medium, and high) were prepared as quality control (QC) samples and analyzed on the same day. The inter-day precision and accuracy were determined with the same three QC samples on three consecutive days.

\section{Calibration curves of ginsenosides in SGF}

A mixed stock solution of Rb1, Rd, G-XVII, F2, Rg3, Cpd $\mathrm{K}$, and $\mathrm{Rh} 2$ was prepared in DMSO. A series of working solutions were prepared with DMSO using dilution factors of 2.5, 5, 10, 20, 40, and 80 from the stock solution. An aliquot $(10 \mu \mathrm{L})$ of each working solution was spiked with $200 \mu \mathrm{L}$ of SGF and processed with $70 \mu \mathrm{L}$ of $0.1 \mathrm{~mol} / \mathrm{L} \mathrm{Na}_{2} \mathrm{CO}_{3}$ as described above. The

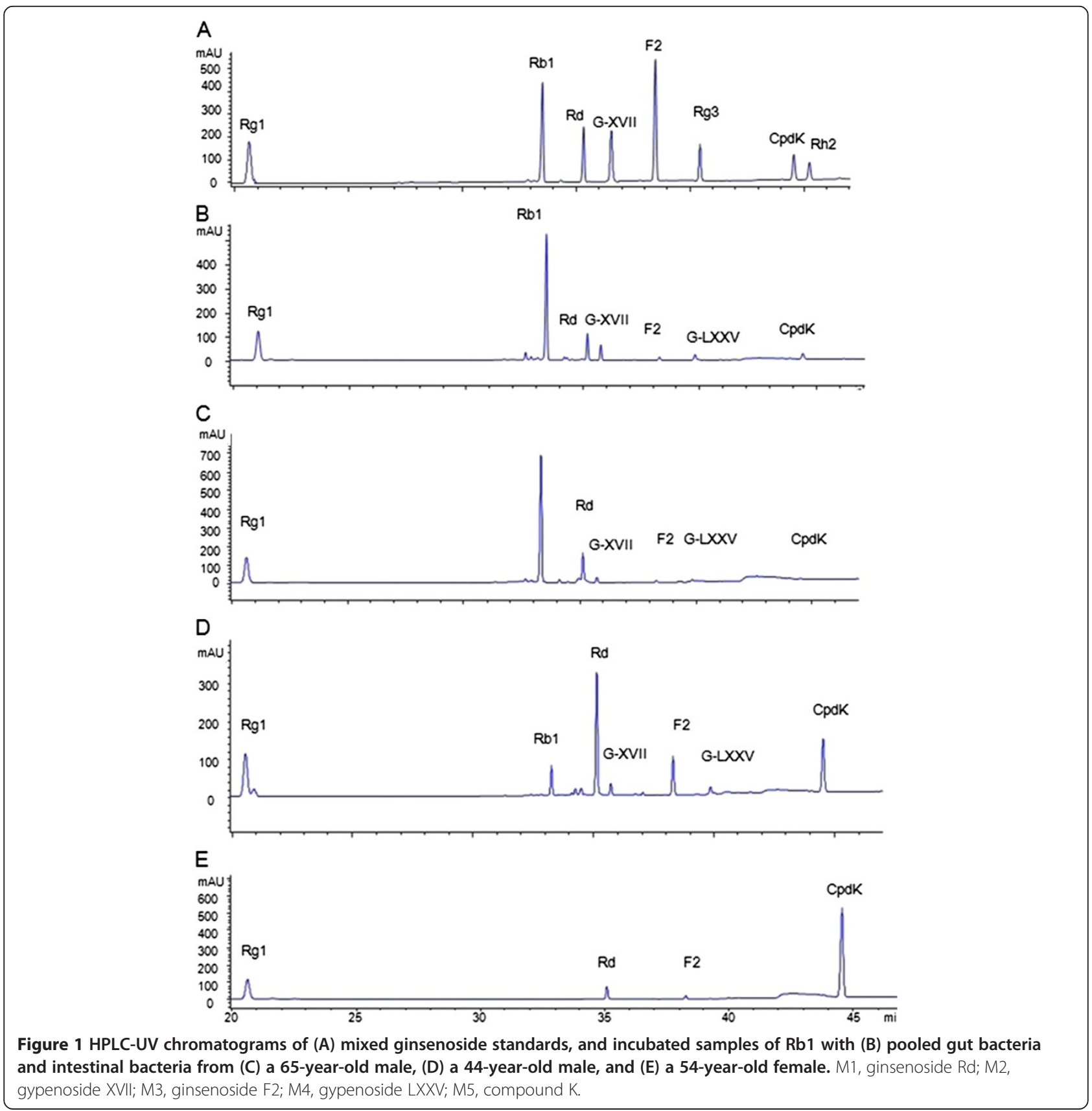


sample $(20 \mu \mathrm{L})$ was injected into the HPLC instrument. A calibration curve was obtained by plotting the peak area of each analyte $(\mathrm{Y})$ against its concentration in SGF (X).

\section{Data analysis}

Data were presented as the means \pm standard deviation (SD) of triplicate analyses (experiments with pooled human gut bacteria or SGF) or individual measurements (experiments on inter-individual variations). Sex and age differences in ginsenoside Rb1 metabolism were compared by Student's $t$-test. Values of $P<0.05$ were considered statistically significant.

\section{Results}

\section{Metabolism of ginsenoside Rb1 by pooled human gut bacteria}

Fecal samples from 50 healthy volunteers ( 25 males and 25 females, range, 45.7-73.7 years) were collected and pooled at 10 individuals each to prepare five human gut bacteria pools. When Rb1 was incubated with pooled human gut bacteria, five peaks (M1-M5) were observed at 35.1, 35.6, 38.2, 39.7, and $44.4 \mathrm{~min}$, respectively, which were absent in control reactions (Figure 1). Under the developed analytical conditions, Rb1 and its metabolites were well-separated from the endogenous interferences of the in vitro anaerobic incubation system. The retention times and characteristic CID fragment ions of the ginsenoside standards and Rb1 metabolites are summarized in Table 1 .

Rb1 was eluted at $33.2 \mathrm{~min}$ and showed its pseudomolecular ion at $m / z 1107\left([\mathrm{M}-\mathrm{H}]^{-}\right)$and chloride adduct ion at $m / z 1143\left([\mathrm{M}+\mathrm{Cl}]^{-}\right)$, corresponding to a molecular weight of 1108 Daltons. The fragment ions at $\mathrm{m} / z$ $945\left(\left[\mathrm{M}-\mathrm{H}_{2} \mathrm{O}-\mathrm{H}\right]^{-}\right), m / z 783\left(\left[\mathrm{M}-2 \mathrm{H}_{2} \mathrm{O}-\mathrm{H}\right]^{-}\right)$, and $m / z$ $621\left(\left[\mathrm{M}-3 \mathrm{H}_{2} \mathrm{O}-\mathrm{H}\right]^{-}\right)$in the CID spectrum corresponded to loss of one, two, and three glucose molecules from $\mathrm{Rb} 1$, respectively.
The retention times and mass spectral profiles of $\mathrm{M} 1$ (35.1 $\mathrm{min})$, M3 (38.2 min), and M5 (44.4 min) were identical to those of Rd, F2, and Cpd K, respectively. The retention time and mass spectral profile of M2 (35.6 min) were identical to those of G-XVII, which was formed from Rb1 by hydrolytic removal of one glucose molecule from the $\mathrm{C}-3$ position of Rb1. Thus, M1-M3 and M5 were unambiguously identified as ginsenosides Rd, G-XVII, F2, and Cpd K, respectively.

M4 was eluted at $39.7 \mathrm{~min}$. The MS spectral profile of M4 was similar to those of M3 (ginsenoside F2) and ginsenoside Rg3 (Table 1), supporting that M4 contained a ginsenoside glycoside with two glucoses. However, the retention time of M4 was different from that of either ginsenoside Rg3 (40.3 min, with two glucoses at the C-3 position) or F2 (38.2 min, with one glucose at the C-3 position and another at the $\mathrm{C}-20$ position) (Figure 1 ). Thus, M4 was tentatively identified as G-LXXV, a metabolite formed from Rb1 with two glucose molecules remaining at the $\mathrm{C}-20$ position.

Taken together, Rb1 biotransformation by human gut bacteria in vitro resulted in the formations of gypenosides as well as metabolites of the Rd pathway.

\section{Time-course of Rb1 metabolism by human gut bacteria}

The calibration curves of Rb1, Rd, F2, G-XVII, and Cpd $\mathrm{K}$ in the in vitro anaerobic incubation system showed good linearity $\left(r^{2}>0.998, P<0.001\right)$ over the concentration ranges tested (Table 2). The overall intra-day and inter-day variations were less than $6 \%$, and recovery was higher than $85 \%$ (except for $\sim 60 \%$ for $10 \mu \mathrm{M}$ Cpd K) (Additional file 1: Table S1).

When Rb1 was incubated with the pooled human gut bacteria (Figure 2A), Rb1 was rapidly eliminated by the human gut bacteria and less than $20 \%$ of the Rb1 remained intact at $12 \mathrm{~h}$. The metabolites from the Rd pathway, $\mathrm{Rd}$ and F2, appeared in the incubations in turn, with $\mathrm{Rd}$ reaching its maximum at $12 \mathrm{~h}$ (representing $~ 50 \%$ of the initial

Table 1 HPLC-ESI-MS and corresponding CID data of ginsenoside standards and the metabolites of ginsenoside Rb1 by human gut bacteria

\begin{tabular}{|c|c|c|c|c|c|}
\hline \multirow[t]{2}{*}{ Retention time (min) } & \multicolumn{3}{|c|}{ MS $(m / z)$} & \multirow[t]{2}{*}{$\operatorname{CID}(m / z)$} & \multirow[t]{2}{*}{ Identity } \\
\hline & {$[\mathrm{M}-\mathrm{H}]^{-}$} & {$\left[\mathrm{M}+\mathrm{Cl}^{-}\right.$} & {$\left[\mathrm{M}+\mathrm{AcO}^{-}\right.$} & & \\
\hline 20.9 & 799 & 835 & 859 & 637[M-H-Glc]-, 619[M-H-Glc- $\left.\mathrm{H}_{2} \mathrm{O}\right]-, 475[\mathrm{M}-\mathrm{H}-2 \mathrm{GlC}]-$ & Ginsenoside Rg1 (IS) \\
\hline 33.2 & 1107 & 1143 & - & 945[M-H-GlC]-, 783[M-H-2Glc]-, 621[M-H-3GlC]- & Ginsenoside Rb1 \\
\hline 35.1 & 945 & 981 & - & $783[\mathrm{M}-\mathrm{H}-\mathrm{GlC}]-, 621[\mathrm{M}-\mathrm{H}-2 \mathrm{Glc}]-$ & Ginsenoside Rd (M1) \\
\hline 35.6 & 945 & 981 & - & $783[\mathrm{M}-\mathrm{H}-\mathrm{GlC}]-, 621[\mathrm{M}-\mathrm{H}-2 \mathrm{Glc}]-$ & Gypenoside XVII (M2) \\
\hline 38.2 & 783 & 819 & 843 & $621[\mathrm{M}-\mathrm{H}-\mathrm{GlC}]-, 459[\mathrm{M}-\mathrm{H}-2 \mathrm{GlC}]-$ & Ginsenoside F2 (M3) \\
\hline 39.7 & 783 & 819 & 843 & $621[\mathrm{M}-\mathrm{H}-\mathrm{Gl}]^{-}, 459[\mathrm{M}-\mathrm{H}-2 \mathrm{Glc}]^{-}$ & Gypenoside LXXV (M4) \\
\hline 40.3 & 783 & 819 & - & $621[\mathrm{M}-\mathrm{H}-\mathrm{GlC}]-, 459[\mathrm{M}-\mathrm{H}-2 \mathrm{GlC}]-$ & Ginsenoside Rg3 \\
\hline 45.4 & 621 & 657 & 681 & 459[M-H-GlC]- & Ginsenoside Rh2 \\
\hline 44.4 & 621 & 657 & 681 & 459[M-H-GlC]- & Compound K (M5) \\
\hline
\end{tabular}


Table 2 Calibration curves of ginsenosides in simulated gastric fluid and an in vitro human gut bacteria incubation system

\begin{tabular}{|c|c|c|c|c|}
\hline Matrix & Analyte & Calibration curve $(\mu \mathrm{M})$ & $r^{2}$ & Concentration range $(\mu \mathrm{M})$ \\
\hline \multirow[t]{7}{*}{ Simulated gastric fluid } & $\mathrm{Rb} 1$ & $Y=3.504 X+6.912$ & 0.9999 & $2.08-167.00$ \\
\hline & $\mathrm{Rd}$ & $Y=3.796 X-3.843$ & 0.9999 & $11.30-3618.00$ \\
\hline & $\mathrm{G}-X \mathrm{XVI}$ & $Y=3.549 X-3.430$ & 0.9999 & $5.21-1666.67$ \\
\hline & F2 & $Y=3.339 X-1.033$ & 0.9999 & $5.21-1666.67$ \\
\hline & Rg3 & $Y=3.377 X+10.180$ & 0.9998 & $1.85-148.30$ \\
\hline & Cpd K & $Y=3.807 X+0.303$ & 0.9999 & $5.21-1666.67$ \\
\hline & $\operatorname{Rh} 2$ & $Y=3.644 X+6.880$ & 0.9999 & $5.21-1666.67$ \\
\hline \multirow[t]{5}{*}{ Human gut bacteria } & $\mathrm{Rb} 1$ & $Y=6.1209 X+0.094$ & 0.9986 & $50.00-800.00$ \\
\hline & $\mathrm{Rd}$ & $Y=7.3891 X+4 E-0.5$ & 0.9998 & $31.25-500.00$ \\
\hline & GXVII & $Y=6.1571 X+0.062$ & 0.9999 & $30.00-200.00$ \\
\hline & F2 & $Y=6.7242 X+0.003$ & 0.9999 & $16.25-260.00$ \\
\hline & Cpd K & $Y=6.7841 X+0.042$ & 0.9945 & $5.16-165.00$ \\
\hline
\end{tabular}

Rb1) followed by the maximum of F2 at relatively low levels (representing $\sim 7 \%$ of the initial Rb1). The amount of $\mathrm{Cpd} \mathrm{K}$ peaked at $36 \mathrm{~h}$. Compared with their respective positional isomers $\mathrm{Rd}$ and F2, G-XVII and G-LXXV formed from the gypenoside pathway reached their maximum levels more rapidly $\left(\mathrm{T}_{\max }: 4\right.$ and $8-12 \mathrm{~h}$, respectively). Because the positional isomers $\mathrm{Rd}$ and GXVII showed similar UV responses, as evidenced by the very close constant coefficients (Table 2), we assumed that F2 and G-LXXV, the positional isomers formed by hydrolytic removal of two glucoses from $\mathrm{C}-3$ and $\mathrm{C}-20$ (F2) and C-3 (G-LXXV), would also have similar UV responses. Thus, the levels of the positional isomers F2 and G-LXXV were calculated using the calibration curve of F2. Both gypenosides were formed at relatively lower levels than their positional isomers. The maximum level of G-XVII was about $10 \%$ of $\mathrm{Rd}$, while that of G-LXXV was half of the peak concentration of F2. Moreover, both gypenosides had disappeared from the incubation system within $24 \mathrm{~h}$, long before Cpd K
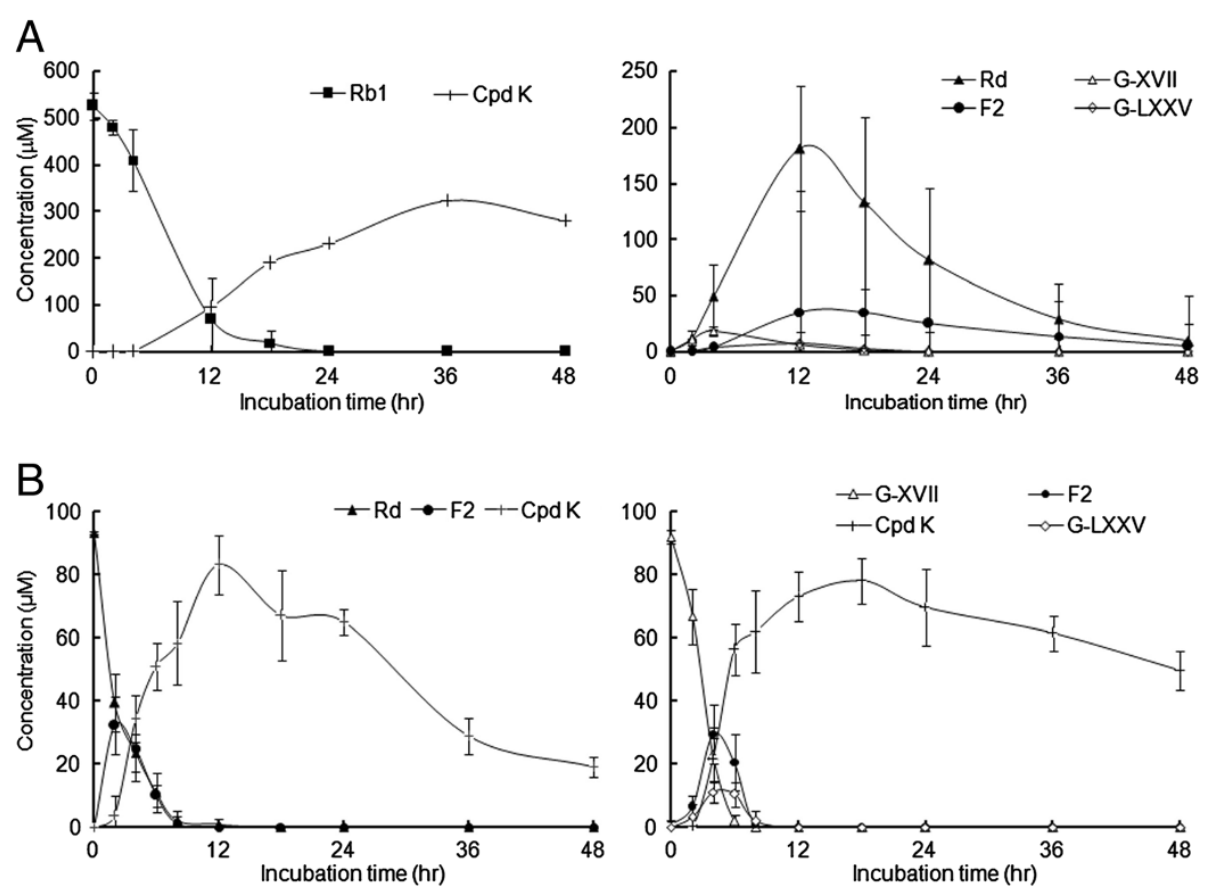

Figure 2 Time-courses of the elimination and metabolite formations of (A) ginsenoside Rb1, and (B) Rd (solid line) and G-XVII (dotted line) in human gut bacteria. 
reached its maximum level at $36 \mathrm{~h}$, while $\mathrm{Rd}$ and F2 were still detectable at $48 \mathrm{~h}$. Thus, the gypenoside pathway should be the minor pathway of Rb1 biotransformation by human gut bacteria.

\section{Biotransformation of Rd and G-XVII by human gut bacteria}

Rd and G-XVII were depleted within 8 h by human gut bacteria, and generated F2 and Cpd $\mathrm{K}$ when incubated separately. The generations of F2 and Cpd K from Rd peaked at 2 and $12 \mathrm{~h}$, respectively, while those generated from G-XVII reached their maximum levels at 4 and $18 \mathrm{~h}$, respectively. The maximum levels of $\mathrm{F} 2$ and $\mathrm{Cpd} \mathrm{K}$ formed from Rd were comparable to those from G-XVII (about 30 and $80 \mu \mathrm{M}$, reflecting $30 \%$ and $80 \%$ of the original amounts of the respective parent compounds) (Figure 2B).
G-LXXV was also generated by human gut bacteria as evidenced by the retention time and mass spectral profile. F2 presented as a major metabolite and the $\mathrm{C}_{\max }$ was two times higher that of G-LXXV (Figure 2B). Therefore, both the G-XVII $\rightarrow$ F2 and G-XVII $\rightarrow$ G-LXXV pathways of G-XVII metabolism existed in the human gut bacteria, with the former as the major pathway in vitro.

\section{Rb1 biotransformation by individual human gut bacterial samples}

When Rb1 was separately incubated with gut bacterial samples from 58 individuals aged 18-92 years (30 females and 28 males; range, 39.6-75.3 years), great inter-individual variations were observed in terms of the remaining $\mathrm{Rb} 1$ and the amounts of metabolites formed via the Rd and gypenoside pathways (Figure 3A). However, when compared by age, there were no significant differences in $\mathrm{Rb} 1$
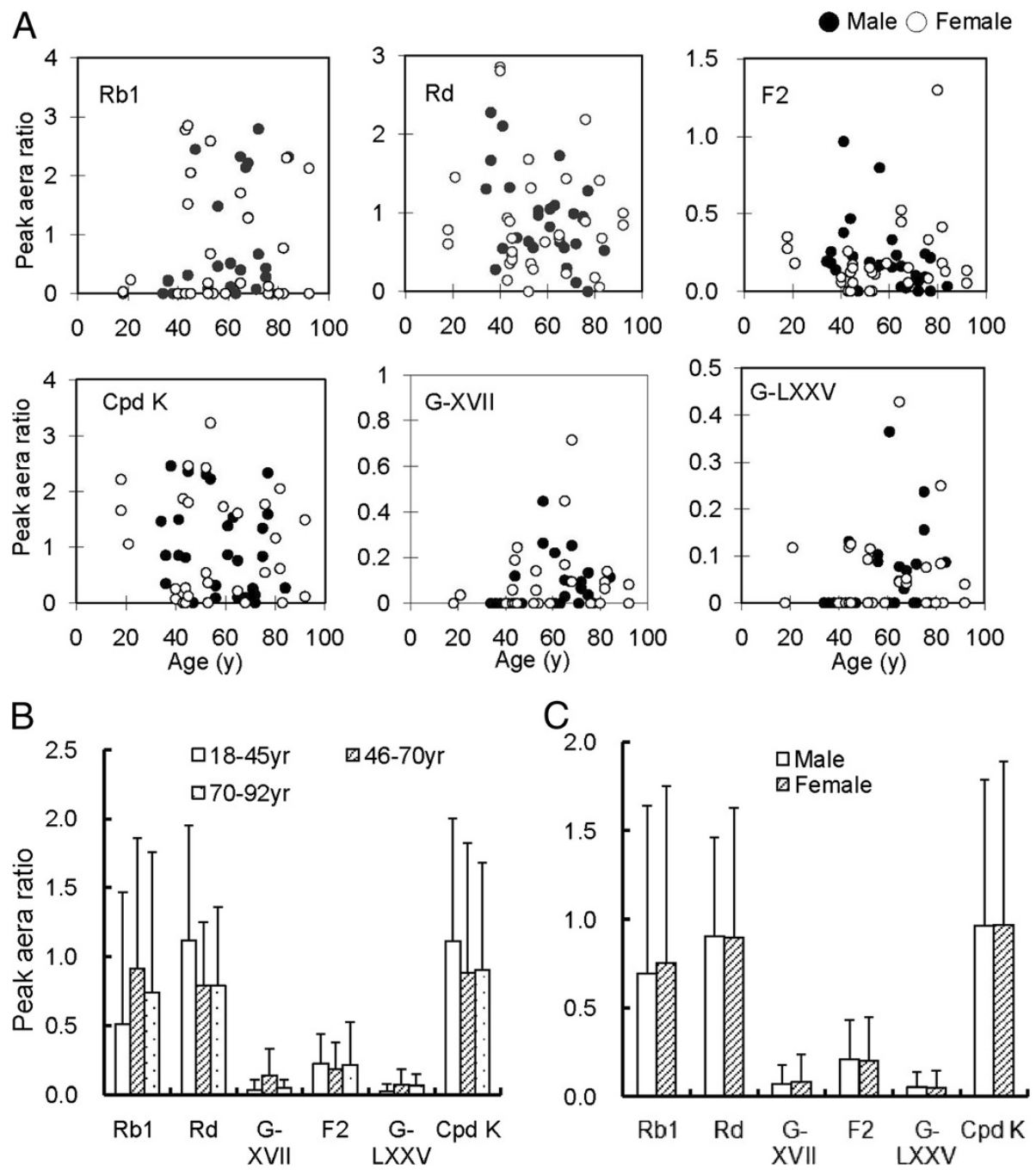

Figure 3 Ginsenoside Rb1 metabolism and its metabolite formation by gut bacteria samples from 58 healthy individuals (A) of different ages (B) and sexes (C). 
elimination and each pathway among individuals aged 18-45 years (20 individuals; range, 29.2-47 years), 4670 years (22 individuals; range, 52.7-65.9 years), and 7192 years (16 individuals; range, 72.6-85.4 years) (Figure 3B). No sex differences ( $P$ values: $0.3 \sim 0.5)$ were observed in Rb1 metabolism and each pathway by human gut bacteria (Figure 3C).

\section{Degradation of Rb1 and Rd in SGF}

The calibration curves of Rb1, Rd, G-XVII, F2, Rg3, Cpd $\mathrm{K}$, and Rh2 in SGF showed good linearity $\left(r^{2}>0.998\right.$, $P<0.001$ ) over the concentration ranges tested (Table 2).

$\mathrm{Rb} 1$ was rapidly degraded under acidic environments to half of its original amount in $1 \mathrm{~h}$, with $<10 \%$ remaining at $3 \mathrm{~h}$ (Figure 4). Ginsenosides F2, Rg3, Cpd K, and Rh2 were all detected in SGF. However, Rd was not detected throughout the incubation period (Figure 4A). When Rd was incubated in SGF, it was rapidly degraded to half its initial amount in $2 \mathrm{~h}$. The same products (F2, Rg3, Cpd K, and Rh2) were generated. In both cases, F2 was the most abundant product in SGF, and the gypenosides were not detected (Figure 4A).

The in vitro bacterial biotransformation experiments suggested the existence of metabolic pathways for Rb1 in human gut bacteria as follows: Rb1 lost one C-20 glucose to generate $\mathrm{Rd}$ (major) and one $\mathrm{C}-3$ glucose to generate G-XVII (minor); Rd lost another C-20 glucose to generate $\mathrm{F} 2$ and then one $\mathrm{C}-3$ glucose to generate Cpd K; G-XVII further lost one C-20 glucose to form F2 (major), one C-3 glucose to generate G-LXXV (minor), or both; both were finally metabolized to Cpd K. However, under acidic conditions, the degradation of $\mathrm{Rb} 1$ was initiated by simultaneous loss of two glucose molecules from both the $\mathrm{C}-3$ and $\mathrm{C}-20$ positions to generate F2 (major) or Rg3 (minor). The metabolic pathway of $\mathrm{Rb} 1$ in human gut bacteria shown in Figure 5A and the degradation pathways of $\mathrm{Rb} 1$ and Rd in SGF shown in Figure $5 \mathrm{~B}$ were proposed for comparison.

\section{Discussion}

Ginsenosides generally have poor oral bioavailability because of their low membrane permeability, active biliary excretion, biotransformation, and so on [12]. Their deglycosylated products formed by bacterial conversion in the gut lumen are more permeable and were demonstrated to be bioactive [36]. As one of the main PPDtype ginsenosides, ginsenoside $\mathrm{Rb} 1$ was deglycosylated via $\mathrm{Rb} 1 \rightarrow \mathrm{Rd} \rightarrow \mathrm{F} 2 \rightarrow \mathrm{Cpd}$ K (Rd pathway) [26,37]. Another pathway via $\mathrm{Rb} 1 \rightarrow \mathrm{G}-\mathrm{XVII} \rightarrow \mathrm{G}-\mathrm{LXXV} / \mathrm{F} 2 \rightarrow \mathrm{Cpd}$ $\mathrm{K}$ has been reported in rats [24], single fungal strains

A
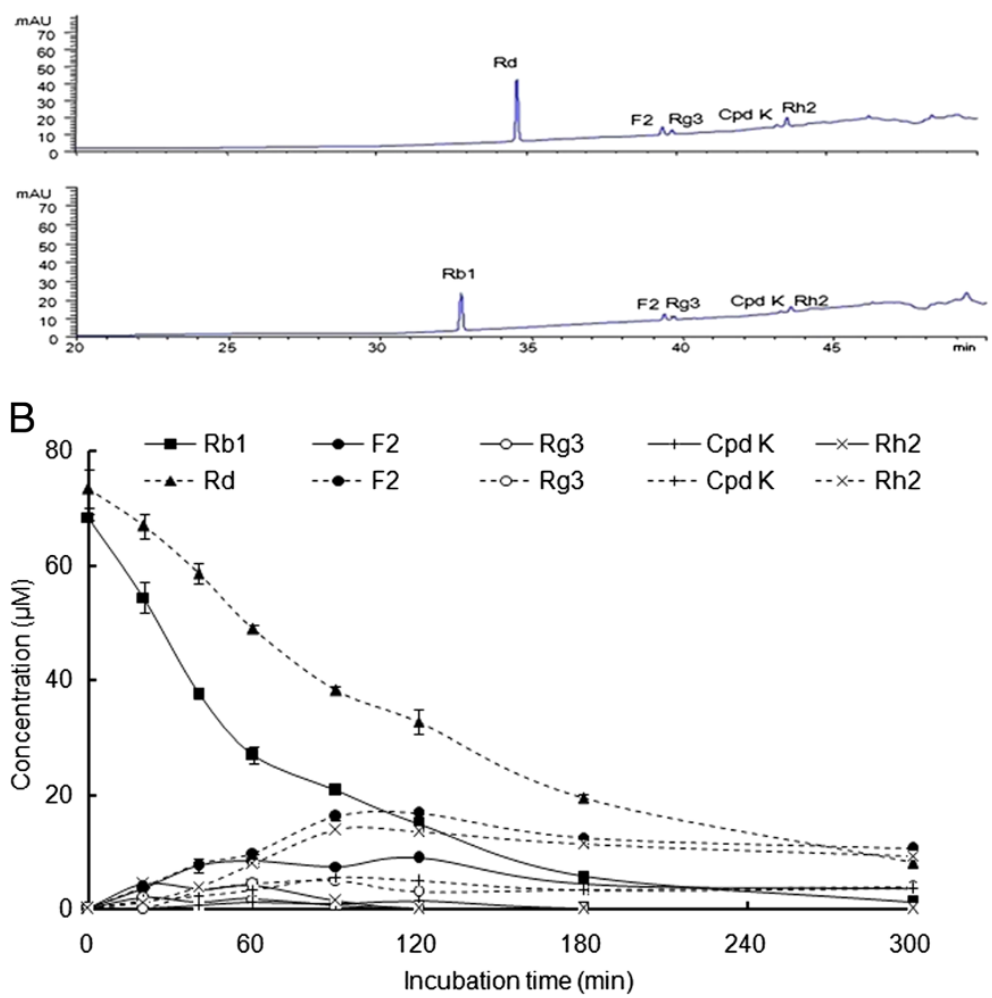

Figure 4 HPLC-UV chromatograms (A) and degradation time-courses (B) of Rb1 (solid line) and Rd (dotted line) in SGF. 

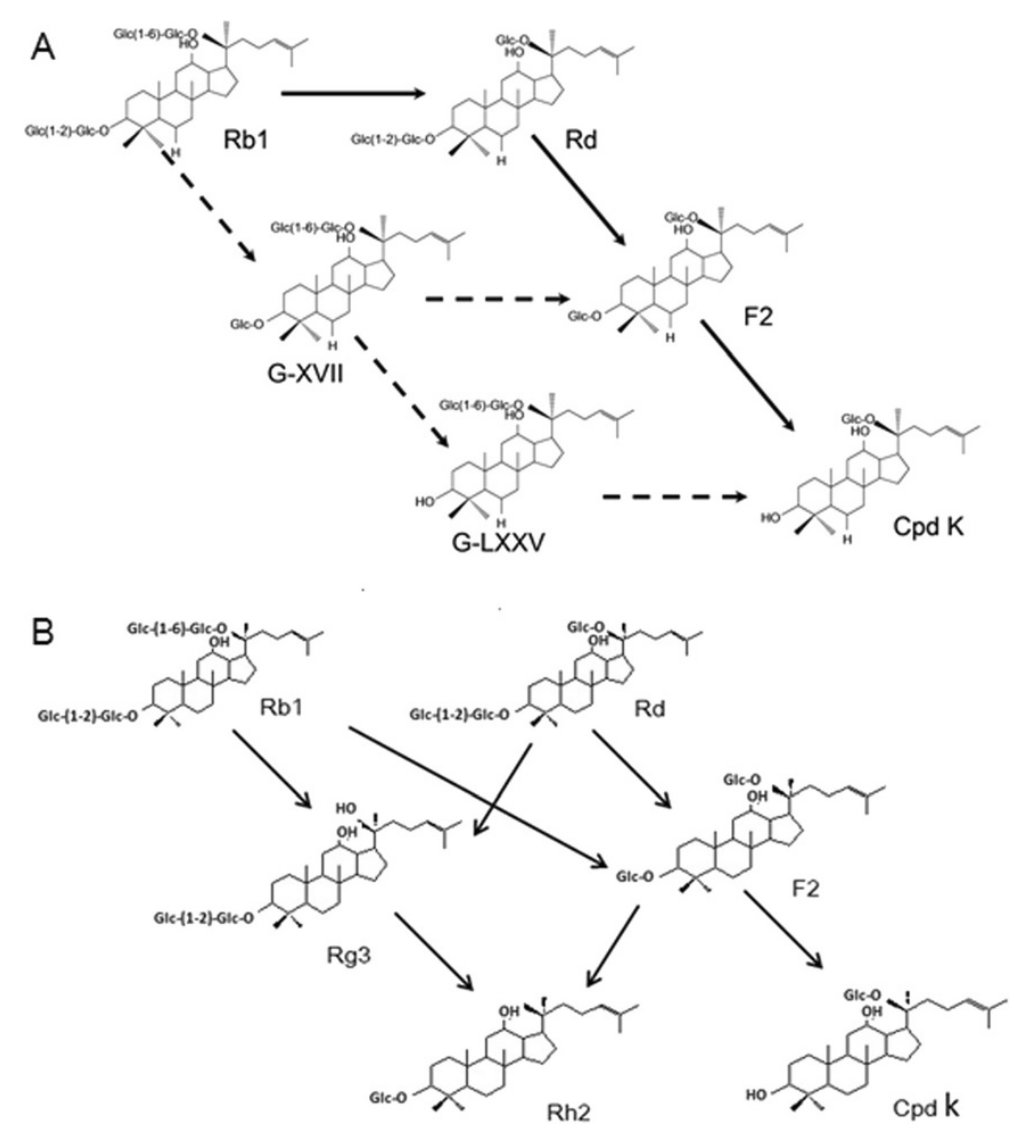

Figure 5 Pathways of (A) Rb1 biotransformation by human intestinal microflora ( $\rightarrow$ major pathway; $\rightarrow-$ minor pathway) and (B) Rb1 degradation in SGF.

[20-22], and bacteria such as Fusobacterium sp. and Bifidobacterium longum sp. [38,39].

In this study with application of both LC-MS and LCDAD techniques, G-XVII and three metabolites (Rd, F2, and Cpd K) were identified from the Rd pathway and GLXXV was tentatively assigned. The existence of both the $\mathrm{Rd}$ and gypenoside pathways of Rb1 metabolism in human gut bacteria was confirmed. The conversion of Rb1 to Cpd K via both G-XVII $\rightarrow$ G-LXXV and G-XVII $\rightarrow$ F2 was also evidenced, for the first time, by the observation that G-XVII produced G-LXXV, F2, and Cpd K, while Rd only generated F2 and Cpd $\mathrm{K}$, in human gut bacteria in vitro.

The gypenoside pathway was demonstrated to be the minor pathway of $\mathrm{Rb} 1$ biotransformation in human gut bacteria by comparing the maximum levels of Rd and F2 with those of their respective positional isomers G-XVII and G-LXXV determined from a time-course study. Moreover, the maximum levels of the gypenoside products were reached more rapidly than the products of the Rd pathway, indicating that the gypenoside pathway was a transient intermediate process. In contrast, the conversion rate of Rd to Cpd K was faster than that of G-XVII to Cpd K, as judged by the times required to reach the maximum level of Cpd K when Rd and G-XVII were separately incubated with human gut bacteria. These findings suggested that the removal of the remote glucose molecule at the C-20 position by human gut bacteria was faster than that of the glucose molecule from the $\mathrm{C}-3$ position, while further cleavage of the second glucose from the $\mathrm{C}-3$ position is a much more difficult process, leading to the formation of F2 much more rapidly than the formation of G-LXXV from G-XVII. Eubacterium sp., Streptococcus sp., and Bifidobacterium sp., which were more potent in hydrolyzing gentiobiose than sophorose, metabolized Rb1 to Cpd K via Rd rather than G-XVII [39]. However, Fusobacterium K-60, which hydrolyzed sophorose more potently than gentiobiose, metabolized Rb1 to Cpd K via G-XVII. Bifidobacteria are probiotics and belong to the predominant gut bacteria, while streptococci and fusobacteria are pathogenic bacteria and are in the minority in healthy humans [40]. This may explain why the Rd pathway was the major pathway, while the gypenoside pathway was the minor pathway of Rb1 in human gut bacteria from healthy volunteers. 
In this study, rapid degradation of Rb1 was observed in SGF and its products including F2, Rg3, Cpd K, and Rh2 were detected, consistent with the findings obtained from previous in vitro [41] and in vivo [42] studies. Rd yielded the same four products in SGF. However, gypenosides were not detected in SGF in both cases, indicating that when $\mathrm{Rb} 1$ is taken orally, gypenosides may only be formed through bacterial biotransformation in the gut lumen.

Great inter-individual variations in Rb1 metabolism by human gut bacteria were observed with both the gypenoside and Rd pathways owing to the great individual variations in the species and amounts of the gut bacteria. These variations showed no differences between sexes and ages.

Thus far, only the Rd pathway has been reported in vivo in the human body $[25,26]$. The minor amount of gypenosides formed by the human gut bacteria may provide beneficial effects for the human body. Thus, further studies are warranted to evaluate the contributions of these gypenosides to the health-promoting effects of ginsenoside $\mathrm{Rb} 1$ in vivo.

\section{Conclusions}

Rb1 was metabolized to G-XVII, F2 (major) or G-LXXL (minor), and finally Cpd K by human gut bacteria in vitro.

\section{Additional file}

Additional file 1: Table S1. Intraday and interday variability for the assays of ginsenoside Rb1, Rd, F2 and compound Kin incubates with human gut bacteria.

\begin{abstract}
Abbreviations
DMSO: Dimethyl sulfoxide; PBS: Phosphate-buffered saline; PPD: 20(S)protopanaxadiol; G-XVII: Gypenoside XVII; G-LXXV: Gypenoside LXXV; Cpd K: Compound K; HPLC-UV: High-performance liquid chromatography with a UV detector; MS: Mass spectrometry; ESI: Electrospray ionization; BHI: Brain heart infusion; SGF: Simulated gastric fluid; QC: Quality control; DAD: Diode array detector; LC/MSD: Liquid chromatograph/mass selective detector; IS: Internal standard; SD: Standard deviation.
\end{abstract}

\section{Competing interests}

The authors declare that they have no competing interests.

\section{Authors' contributions}

RY conceived the study. JPCL, YTW, and RY designed the study. WIL carried out the ginsenoside Rb1 biotransformation by pooled and individual human gut bacteria. HS carried out the experiments on metabolism by human gut bacteria and acidic stability. JQR collected the human fecal samples and prepared bacterial suspensions. SLL and JPCL performed the statistical analysis. WIL, HS, and RY wrote the manuscript. All authors read and approved the final manuscript.

\section{Acknowledgements}

This work was financially supported by the Science and Technology Development Fund of Macao SAR (Ref. No. 043/2011/A2), the Research Committee of University of Macau (Ref. No. MYRG162(Y3-L2)-ICMS11-YR), and the National Natural Science Foundation of China (Grant Nos. 81274068 \& 81202920)

\section{Author details}

${ }^{1}$ State Key Laboratory of Quality Research in Chinese Medicine, Institute of Chinese Medical Sciences, University of Macau, Macao, China. ${ }^{2}$ Department of Pharmaceutical Analysis \& Metabolomics, Jiangsu Provincial Academy of Traditional Chinese Medicine, Nanjing, Jiangsu, China. ${ }^{3}$ Clinical Laboratory, Kiang Wu Hospital, Estrada do Repouso, Macao, China.

Received: 12 July 2013 Accepted: 21 November 2013

Published: 23 November 2013

\section{References}

1. Yang WZ, Ye M, Qiao X, Liu CF, Miao WJ, Bo T, Tao HY, Guo DA: A strategy for efficient discovery of new natural compounds by integrating orthogonal column chromatography and liquid chromatography/mass spectrometry analysis: its application in Panax ginseng, Panax quinquefolium and Panax notoginseng to characterize 437 potential new ginsenosides. Anal Chim Acta 2012, 739:56-66.

2. Shi W, Wang YT, Li J, Zhang HQ, Ding L: Investigation of ginsenosides in different parts and ages of Panax ginseng. Food Chem 2007, 102:664-668.

3. Wang CZ, Wu JA, McEntee E, Yuan CS: Saponins composition in American Ginseng leaf and berry assayed by high-performance liquid chromatography. J Agric Food Chem 2006, 6:2261-2266.

4. Xie YY, Luo D, Cheng YJ, Ma JF, Wang YM, Liang QL, Luo GA: Steaminginduced chemical transformations and holistic quality assessment of red Ginseng derived from Panax ginseng by means of HPLC-ESI-MS/MSnbased multicomponent quantification fingerprint. J Agric Food Chem 2012, 33:8213-8224.

5. Jiang Z, Wang Y, Zhang X, Peng T, Lu Y, Leng J, Xie Q: Preventive and therapeutic effects of ginsenoside rb1 for neural injury during cerebral infarction in rats. Am J Chin Med 2013, 2:341-352.

6. Shen L, Xiong Y, Wang DQ, Howles P, Basford JE, Wang J, Xiong YQ, Hui DY, Woods SC, Liu M: Ginsenoside Rb1 reduces fatty liver by activating AMPactivated protein kinase in obese rats. J Lipid Res 2013, 5:1430-1438.

7. Li QY, Chen L, Fu WH, Li ZD, Wang B, Shi XJ, Zhong MK: Ginsenoside Rb1 inhibits proliferation and inflammatory responses in rat aortic smooth muscle cells. J Agric Food Chem 2011, 11:6312-6318.

8. VanDuynhoven J, Vaughan EE, Jacobs DM, Kemperman RA, Van Velzen EJ, Gross G, Roger LC, Possemiers S, Smilde AK, Doré J, Westerhuis JA, Van de Wiele T: Metabolic fate of polyphenols in the human superorganism. Proc Natl Acad Sci U S A 2011, 108:4531-4538.

9. Hidalgo M, Oruna-Concha MJ, Kolida S, Walton GE, Kallithraka S, Spencer JP, de Pascual-Teresa S: Metabolism of anthocyanins by human gut microflora and their influence on gut bacterial growth. J Agric Food Chem 2012, 15:3882-3890.

10. Sánchez-Patán F, Cueva C, Monagas M, Walton GE, Gibson GR, QuintanillaLópez JE, Lebrón-Aguilar R, Martín-Álvarez PJ, Moreno-Arribas MV, Bartolomé $B$ : In vitro fermentation of a red wine extract by human gut microbiota: changes in microbial groups and formation of phenolic metabolites. J Agric Food Chem 2012, 9:2136-2147.

11. Selma MV, Espín JC, Tomás-Barberán FA: Interaction between phenolics and gut microbiota: role in human health. J Agric Food Chem 2009, 15:6485-6501.

12. Liu H, Yang J, Du F, Gao X, Ma X, Huang Y, Xu F, Niu W, Wang F, Mao Y, Sun Y, Lu T, Liu C, Zhang B, Li C: Absorption and disposition of ginsenosides after oral administration of Panax notoginseng extract to rats. Drug Metab Dispos 2009, 37:2290-2298.

13. Wakabayashi $\mathrm{C}$, Hasegawa H, Murata J, Saiki I: In vivo antimetastatic action of ginseng protopanaxadiol saponins is based on their intestinal bacterial metabolites after oral administration. Oncol Res 1997, 9:411-417.

14. Lee GW, Yoo MH, Shin KC, Kim KR, Kim YS, Lee KW, Oh DK: $\beta$-Glucosidase from Penicillium aculeatum hydrolyzes exo-, 3-O-, and 6-O- $\beta$-glucosides but not 20-O- $\beta$-glucoside and other glycosides of ginsenosides. Appl Microbiol Biotechnol 2013. DOl: 10.1007/s00253-013-4828-7.

15. Lee IK, Kang KA, Lim CM, Kim KC, Kim HS, Kim DH, Kim BJ, Chang WY, Choi $\mathrm{JH}$, Hyun JW: Compound K, a metabolite of ginseng saponin, induces mitochondria-dependent and caspase-dependent apoptosis via the generation of reactive oxygen species in human colon cancer cells. Int J Mol Sci 2011, 11:4916-4931

16. Niu T, Smith DL, Yang Z, Gao S, Yin T, Jiang ZH, You M, Gibbs RA, Petrosino JF, Hu M: Bioactivity and bioavailability of ginsenosides are dependent 
on the glycosidase activities of the $\mathrm{A} / \mathrm{J}$ mouse intestinal microbiome defined by pyrosequencing. Pharm Res 2013, 30:836-846.

17. Hasegawa $\mathrm{H}$ : Proof of the mysterious efficacy of ginseng: basic and clinical trials: metabolic activation of ginsenoside: deglycosylation by intestinal bacteria and esterification with fatty acid. J Pharmacol Sci 2004 95:153-157.

18. Hasegawa $H$, Sung $\mathrm{JH}$, Matsumiya S, Uchiyama M: Main ginseng saponin metabolites formed by intestinal bacteria. Planta Med 1996, 62:453-457.

19. Hasegawa $H$, Sung $J H$, Benno $Y$ : Role of human intestinal prevotella oris in hydrolyzing ginseng saponins. Planta Med 1997, 63:436-440.

20. Chen GT, Song Y, Lu ZQ, Zhang JQ, Huang HL, Wu L, Guo DA: Microbial transformation of ginsenoside Rb1 by Acremonium strictum. Appl Microbiol Biotechnol 2008, 77:1345-1350.

21. Hou JG, Xue JJ, Sun MQ, Wang CY, Liu L, Zhang DL, Lee MR, Gu LJ, Wang $C L$, Wang YB, Zheng Y, Li W, Sung CK: Highly selective microbial transformation of major ginsenoside $\mathrm{Rb} 1$ to gypenoside LXXV by Esteya vermicola CNU120806. J Appl Microbiol 2012, 113:807-814.

22. Zhao X, Gao J, Song C, Fang Q, Wang N, Zhao T, Liu D, Zhou Y: Fungal sensitivity to and enzymatic deglycosylation of ginsenosides. Phytochemistry 2012, 78:65-71.

23. Karikura M, Miyase T, Tanizawa H, Taniyama T, Takino Y: Studies on absorption, distribution, excretion and metabolism of ginseng saponins: VII: comparison of the decomposition modes of ginsenoside- $\mathrm{Rb} 1 \mathrm{and}-\mathrm{Rb} 2$ in the digestive tract of rats. Biol Pharm Bull 1991, 39:2357-2361.

24. Chen G, Yang M, Song Y, Lu Z, Zhang J, Huang H, Guan S, Wu L, Guo DA: Comparative analysis on microbial and rat metabolism of ginsenoside $\mathrm{Rb} 1$ by high-performance liquid chromatography coupled with tandem mass spectrometry. Biomed Chromatogr 2008, 22:779-785.

25. Lee J, Lee E, Kim D, Lee J, Yoo J, Koh B: Studies on absorption, distribution and metabolism of ginseng in humans after oral administration. J Ethnopharmacol 2009, 122:143-148.

26. Tawab MA, Bahr U, Karas M, Wurglics M, Schubert-Zsilavecz M: Degradation of ginsenosides in humans after oral administration. Drug Metab Dispos 2003, 31:1065-1071.

27. Ye R, Kong X, Yang Q, Zhang Y, Han J, Zhao G: Ginsenoside Rd attenuates redox imbalance and improves stroke outcome after focal cerebral ischemia in aged mice. Neuropharmacology 2011, 61:815-824.

28. Qin R, Zhang J, Li C, Zhang X, Xiong A, Huang F, Yin Z, Li K, Qin W, Chen M, Zhang S, Liang L, Zhang H, Nie H, Ye W: Protective effects of gypenosides against fatty liver disease induced by high fat and cholesterol diet and alcohol in rats. Arch Pharm Res 2012, 35:1241-1250.

29. Zhang GL, Deng JP, Wang BH, Zhao ZW, Li J, Gao L, Liu BL, Xiong JR, Guo XD Yan ZQ, Gao GD: Gypenosides improve cognitive impairment induced by chronic cerebral hypoperfusion in rats by suppressing oxidative stress and astrocytic activation. Behav Pharmacol 2011, 22:633-644

30. Pereira JM, Mejia-Ariza R, llevbare GA, McGettigan HE, Sriranganathan N, Taylor LS, Davis RM, Edgar KJ: Interplay of degradation, dissolution and stabilization of clarithromycin and its amorphous solid dispersions. Mol Pharm 2013. DOl: 10.1021/mp400441d.

31. Pietta $P$, Mauri $P$, Rava $A$ : Hydrolysis of ginsenosides in artificial gastric fluid monitored by HPLC. J Chromatogr 1986, 362:291-297.

32. Miyamoto E, Odashima S, Kitagawa I, Tsuji A: Stability kinetics of ginsenosides in aqueous solution. J Pharm Sci 1984, 73:409-410.

33. Zhou RN, Song YL, Ruan JQ, Wang YT, Yan R: Pharmacokinetic evidence on contribution of intestinal bacterial conversion to beneficial actions of astragaloside IV, a marker compound of Astragali Radix, in traditional oral use of the herb. Drug Metab Pharmacok 2012, 27:586-597.

34. Kim KA, Jung $H$, Park SH, Ahn YT, Huh CS, Kim DH: Comparative analysis of the gut microbiota in people with different levels of ginsenoside $\mathrm{Rb} 1$ degradation to compound K. PLoS One 2013, 8:e62409.

35. Pharmacopoeia Commission of China: Appendix. In Chinese Pharmacopoeia II. Beijing: China Medical Science Press; 2010:85

36. Hasegawa H, Uchiyama M: Antimetastatic efficacy of orally administered ginsenoside $\mathrm{Rb} 1$ in dependence on intestinal bacterial hydrolyzing potential and significance of treatment with an active bacterial metabolite. Planta Med 1998, 64:696-700.

37. Qian TX, Jiang ZH, Cai ZW: High-performance liquid chromatography coupled with tandem mass spectrometry applied for metabolic study of ginsenoside Rb1 on rat. Anal Biochem 2006, 352:87-96.

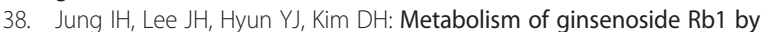
human intestinal microflora and cloning of its metabolizing $\beta$-D- glucosidase from Bifidobacterium longum H-1. Biol Pharm Bull 2012, 35:573-581.

39. Bae EA, Park SY, Kim DH: Constitutive beta-glucosidases hydrolyzing ginsenoside Rb1 and Rb2 from human intestinal bacteria. Biol Pharm Bull 2000, 23:1481-1485.

40. Claesson MJ, Cusack S, O'Sullivan O, Greene-Diniz R, De Weerd H, Flannery E, Marchesi JR, Falush D, Dinan T, Fitzgerald G, Stanton C, Van Sinderen D, O'Connor M, Harnedy N, O'Connor K, Henry C, O'Mahony D, Fitzgerald AP, Shanahan F, Twomey C, Hill C, Ross RP, OToole PW: Composition, variability, and temporal stability of the intestinal microbiota of the elderly. Proc Natl Acad Sci U S A 2011, 108:4586-4591.

41. Zhang X, Song F, Cui M, Liu Z, Liu S: Investigation of the hydrolysis of ginsenosides by high performance liquid chromatography-electospray ionization mass spectrometry. Planta Med 2007, 73:1225-1229.

42. Qian TX, Cai ZW: Biotransformation of ginsenosides Rb1, Rg3 and Rh2 in rat gastrointestinal tracts. Chin Med 2010, 5:19.

doi:10.1186/1749-8546-8-22

Cite this article as: Shen et al:: Biotransformation of ginsenoside Rb1 via the gypenoside pathway by human gut bacteria. Chinese Medicine 2013 8:22.

\section{Submit your next manuscript to BioMed Central and take full advantage of:}

- Convenient online submission

- Thorough peer review

- No space constraints or color figure charges

- Immediate publication on acceptance

- Inclusion in PubMed, CAS, Scopus and Google Scholar

- Research which is freely available for redistribution

Submit your manuscript at www.biomedcentral.com/submit
C BioMed Central 